Olivet Nazarene University

Digital Commons @ Olivet

Student Scholarship - Family and Consumer

Science

Family and Consumer Science

$5-11-2019$

\title{
The relationship between food allergy reporting and allergen friendly food availability in a university foodservice
}

\author{
Abigail Brummel \\ Olivet Nazarene University, abigail.brummel@gmail.com
}

Follow this and additional works at: https://digitalcommons.olivet.edu/facs_stsc

Part of the Dietetics and Clinical Nutrition Commons, Food Studies Commons, and the Nutrition Commons

\section{Recommended Citation}

Brummel, Abigail, "The relationship between food allergy reporting and allergen friendly food availability in a university foodservice" (2019). Student Scholarship - Family and Consumer Science. 1.

https://digitalcommons.olivet.edu/facs_stsc/1

This Article is brought to you for free and open access by the Family and Consumer Science at Digital Commons @ Olivet. It has been accepted for inclusion in Student Scholarship - Family and Consumer Science by an authorized administrator of Digital Commons @ Olivet. For more information, please contact digitalcommons@olivet.edu. 


\title{
THE RELATIONSHIP BETWEEN FOOD ALLERGY REPORTING AND ALLERGEN FRIENDLY FOOD AVAILABILITY IN A UNIVERSITY FOODSERVICE
}

by

\author{
Abigail Brummel \\ Departmental Honors Capstone Research Project \\ Submitted to the Faculty of \\ Department of Family and Consumer Science \\ Olivet Nazarene University
}

in partial fulfillment of the requirements for

DEPARTMENTAL HONORS

MAY 11, 2019

BACHELOR OF SCIENCE in DIETETICS

Research Advisor (Printed)

Department Chair (Printed)

Department Faculty (Printed)

Department Faculty (Printed)
Signature

Signature

Signature

Signature
Date

Date

Date

Date 


\section{ACKNOWLEDGEMENTS}

I first want to give a special thank you to my research advisor, Dr. Catherine Anstrom for all of her support, guidance, and patience throughout the research process. I would also like to thank Dr. Alison Young Reusser for her guidance on interpreting the qualitative data for the research study. I would like to extend a thank you to Sam Cross and Lela Fausze, of Sodexo, for taking the time to participate in the interview. I would like to thank all 94 survey participants for willingly participating in the study. Finally, I would like to thank Olivet Nazarene University's Family and Consumer Sciences department for their support and allowing me to purse this research opportunity. 


\begin{abstract}
Food allergies grew 18\% from 1997-2007 (Centers for Disease Control and Prevention, 2013). As the prevalence of food allergies continues to grow, college students with diagnosed food allergies are having difficulty finding allergen friendly foods in college campus foodservice (Food Allergy Research \& Education, 2014). In order to find the relationship between food allergy communication and prevalence of allergen friendly food on a college campus, a mixed method design was used for this research study. A researcher constructed questionnaire was piloted to senior dietetic students $(n=8)$ for question clarity. Questions were then adjusted for clarity. A convenience sample of undergraduate students was recruited from a small Midwestern university ( $n=94)$. Questions addressed diagnosed food allergies, reporting to campus food service, and availability of allergen friendly food. A frequency distribution was used to organize the data. Thirty six of $94(38.3 \%)$ participants reported having a food allergy or intolerance, 28 of $36(77.8 \%)$ did not report their food allergy or intolerance to foodservice, four $(11 \%)$ did report their food allergy or intolerance to foodservice, four $(11 \%)$ did not respond to this question. Of the four $(11 \%)$ reporting their allergy or intolerance, three $(75 \%)$ found allergen friendly foods available on campus, one (3.6\%) did not. Qualitatively, an interview with the campus dietitian and university food manager was conducted. Questions asked included "How do students report food allergies to foodservice?"; "How are food allergy accommodations handled"? Responses were transcribed, coded and reviewed for themes concerning food allergy reporting and allergen friendly food availability. Themes revealed pathways to report food allergies are available via campus dietitian or student development. Once reported action is
\end{abstract}


taken. Reporting pathways are available but underutilized. Availability of allergen friendly foods can improve through student communication with Foodservice. An emerging problem may be that college students underreport food allergies. 


\section{TABLE OF CONTENTS}

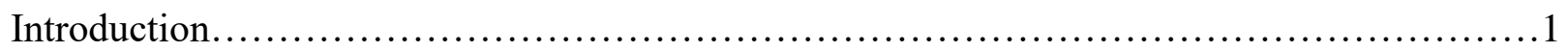

Literature Review..........................................................6

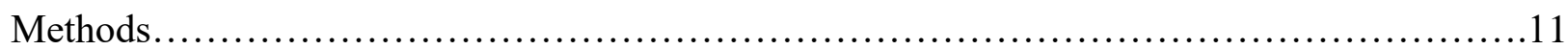

Results..................................................................... 12

Discussion.................................................................. 13

Explanation of results.................................................. 13

Limitations.............................................................. 14

Implication of results..................................................

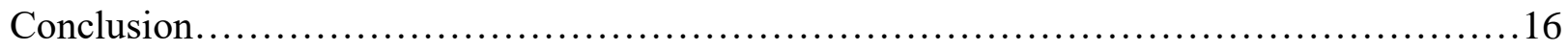

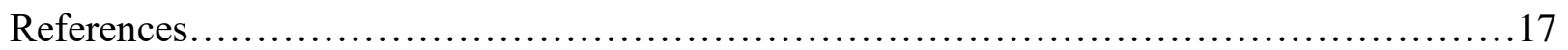

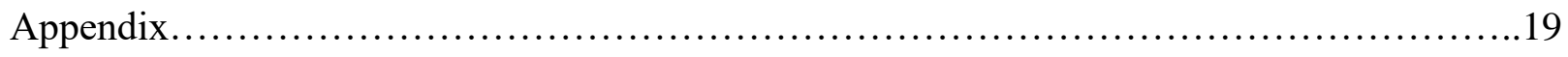

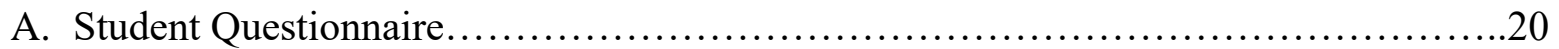

B. Qualitative Questions for Food Service.....................................22 


\section{INTRODUCTION}

Food allergies are defined as an adverse response to food triggered by the body's immune system. An adverse response typically happens as a result of the immune system over reacting to a protein in a certain food (American Academy of Allergy Asthma and Immunology, n.d.). Any food can cause a food allergy or reaction (Dow, 2019). The top eight food foods that cause $90 \%$ of food related reactions are milk, eggs, peanuts, wheat, fish, soy, crustaceans, and tree nuts. Food allergy reactions can involve the respiratory tract, skin, and digestive system. Food allergies are more common in children than adults, but this does not mean they cannot develop in adults. Food allergies can start at any age, with the most likely to strike in adults being an allergy to shellfish (Dow). Symptoms of a food allergy reaction involving the respiratory tract include itching or tightness of the throat, shortness of breath, dry or raspy cough, runny nose, and wheezing. Symptoms of a food allergy reaction involving the skin include swelling of the lips, tongue, and face, itchy eyes, hives, and rash. Symptoms of an allergic reaction involving the digestive system include abdominal pain, nausea, vomiting, and diarrhea (Dobler, 1991). Food allergy reactions can include numerous symptoms and some cases can cause anaphylaxis, a lifethreatening allergic reaction (Koerner \& Munoz-Furlong, 1998). Some reactions can range in severity and can be mild the first time a food is consumed but severe the second time a food is consumed. Symptoms can be either more or less severe than before (Dow).

\section{Diagnosis}

Food allergies can be difficult to diagnose. Guidelines for the diagnosis and management of food allergies was not published until 2010 (Togias et al., 2017). The first step to diagnose a 
food allergy is speaking with a doctor or allergist and answering questions to identify foods that may cause an allergic reaction. The next step is a series of tests to confirm an allergy is present. Two of these tests used include a serum IgE concentration test and a Radioallergosorbent test.

The IgE tests the levels of the antibody for a specific food in the blood that could possibly be causing a reaction. The IgE test does not reveal why the antibody levels for a specific food in the blood could be high. The Radioallergosorbent tests how the blood response to a specific food protein with specific antibodies. High levels of antibodies in response to the exposure of the food protein indicate a possible allergy to that food (Koerner \& Munoz-Furlong, 1998). A skin prick test involves introducing a specific food protein to the top layer of the skin. The area that is pricked is then observed for a reaction (Dobler, 1991). A reaction to the skin prick test could include hives or red, itchy skin. The gold standard for testing is the double-blind, placebocontrolled food challenge. This test involves eating a food with a specific protein and a placebo given at different times. The individual is then observed for reactions. Open challenges are similar to the double-blind test but use higher dosages of food proteins and the individual is aware of what they are eating. Food Challenges, although the gold standard, take time and are only done in clinics that can properly respond to a severe allergic reaction (Dow, 2019).

Elimination diets are also used to try to identify food allergies. There are a plethora of other tests that are not proven to give accurate results. One of these is the IgG test which involves a blood sample that is analyzed for the presence of food-specific immunoglobulin $G$ antibodies. The immunoglobulin $\mathrm{G}$ antibodies have been found in allergic and non-allergic individuals. Allergists believe this is the body's response to eating a specific food. This test is controversial and has not been proven to give accurate results (Koerner \& Munoz-Furlong, 1998). 
Self-diagnosis of food allergies happens when an individual tries to diagnose and treat their own suspected food allergies. This can lead to unnecessary restrictions of foods. Evidence shows that over $20 \%$ of individuals are modifying their diet due to perceived food allergy (Collins, 2016). Unnecessary diet restriction can lead to nutritional deficiencies, reduced quality of life, or significant economic impact (Collins). One of the biggest economic impacts of unnecessary dietary restriction financial. There may be unnecessary financial burden due to having to buy certain alternative foods. It is essential for the registered dietitian to use evidencebased practices to prevent unnecessary over-restriction in the diet that could lead to nutritional deficiencies, malnutrition, or increased unnecessary anxiety (Collins). All food allergies should be diagnosed by a qualified medical professional. Not only do individuals self-diagnose food allergies, but food intolerance can be self-diagnosed as well. Some individuals self-diagnose themselves with a food intolerance (Koerner \& Munoz-Furlong, 1998).

An intolerance, such as a lactose intolerance, have different mechanisms of action than food allergies. Often times people refer to a food intolerance has an allergy (Winthrope, 2013). Where food allergies involve the immune system, food intolerances involve the digestive system. An intolerance typically occurs when an individual has difficulty digesting a certain food (American Academy of Allergy Asthma and Immunology, n.d.). Sometimes individuals can ingest the offending food without experiencing any or experiencing just a few symptoms (Koerner \& Munoz-Furlong, 1998).

Food allergies are a growing concern in the United States and seems to be more prevalent than ever. Food allergies are a major health problem that affect children and adults. (Togias et al., 2017). Many individuals think the increase of food allergies is a result of an 
increase in reporting and that the rates are not actually increasing. Others think the increase in

food allergies is a result of early introduction and frequent exposure to certain foods (Koerner \& Munoz-Furlong, 1998). However, there is emerging data that strongly suggests that peanut allergy or other food allergies can be prevented through early exposure (Togias et al.). With the increase in food allergies over the past several years, there has also been an increase of food allergy-related emergencies involving college students. As many as $16 \%$ to $18 \%$ of food allergy reactions occur in a school setting (Collins, 2016). According to Winthrope (2013), this can happen as a result of a lack of communication between students, healthcare providers, and university food service. With an increasing number of individuals with diagnosed food allergies growing and reactions related to food allergies, college aged individuals may be at risk for food allergy reaction, as many students are required to invest in the university meal plan. Students who live on campus in residence halls may not have access to a kitchen and may be required to eat in a university dining hall. This means that they rely on university dining centers for a majority of their meals and dietary needs. College students with diagnosed food allergies are having more difficulty finding allergen friendly foods in college campus foodservice (Food Allergy Research \& Education, 2014).

\section{Cross Contamination}

In a school setting, cross-contamination is a major concern. Cross-contamination occurs when a food comes in contact with another food. An example of this is when fruit comes into contact with the gluten protein as a result of not switching cutting boards. Cross-contamination can be caused by trace amounts that is often invisible. Trace amounts of an allergen can cause a severe reaction in individuals diagnosed with food allergies. There are government regulations 
that require cleaning up thoroughly between production of each food item. However, even then small amounts of food can become lodged in equipment if not cleaned correctly (Koerner \& Muńoz-Furlong, 1998). Awareness of allergens becomes increasingly important as a result of cross-contamination, especially in a school setting. Not only awareness, but communication with food handling staff and food managers becomes important as well. Communication of food allergies and preparation is critical when it comes to a student's safety, health, and well-being on a college campus. Without communication, there can be little to no food allergy accommodations.

The purpose of this study was to understand the relationship between communication of food allergies between students and food handlers in university foodservice and availability of allergen friendly foods on a college campus in order to increase the availability of allergen friendly foods for students with food allergies/intolerances and decrease the risk of allergic reactions. Participants were recruited from a small mid-western university. This was accomplished through administering a student survey to three Family and Consumer Science classes on campus. The survey assessed the prevalence of food allergies and intolerances as well as if there was communication between the student and food handlers. An interview was conducted with the campus dietitian and the manager of foodservice on campus in order to understand the process and steps of communicating a food allergy and creating availability for a student. This research study was guided by the following research question.

\section{Research Question:}

1. How does food allergy communication between students and food service impact the availability of allergen friendly foods on a college campus? 


\section{LITERATURE REVIEW}

\section{Food allergy and food allergy attitudes among college students}

Food allergies are a growing concern worldwide among the general population. There has been an increase over the past two decades and as the number of food allergies increases, so does the incidence of adverse reactions. About 30,000 emergency department visits for food allergy reactions has been estimated, with 150-200 of those being fatal. With the increase, college students are also at increased risk for food allergy reactions. Between the years 1994 and 2006, there were 63 severe or fatal allergic reactions related to food allergies. Of those 63 reactions, 16 occurred in students of the age 18-22 and half of them occurred on a college campus (Greenhawt, Singer, \& Baptist, 2009).

With little being known about food allergies among college students, Greenhawt et al. studied food allergies and food allergy attitudes among college students. The researchers distributed a 32-question survey electronically to 14,990 undergraduate students throughout Michigan. The researchers obtained responses from 513 undergraduate students. Of the 513 undergraduate students, 293 (57\%) reported a known food allergy. Two hundred and eightyseven of the 293 were included for further questions. The study was unclear about what happened to the other six participants. Of the 287 who were included for further questions, 122 (42\%) experienced an allergic reaction to food while enrolled in college. Of the $122(42 \%)$ who experienced an allergic reaction to food while enrolled 76 (62.3\%) occurred while on campus, and $46(37.7 \%)$ occurred while off campus (Greenhawt et al.). Forty-three percent of the students who were studied did not prepare their own food, and 57\% prepared their own food more often 
than not. Meaning they made their own food most of the time. Of the $43 \%$ who did not prepare their own food, only $24 \%$ had communicated their food allergy to the food handlers and food managers (Greenhawt et al.). This means that three out of four college students did not report or communicate their food allergy with the food service or campus dietitian.

Greenhawt et al. (2009) also asked students questions regarding the information provided within the dining hall about food being served. Of the 287 students who were questioned, 33 (11.5\%) reported that the dining hall foods were labeled with allergen content. One hundred and five $(36.6 \%)$ of the 287 students reported that an alternative main course dish was available to students with food allergies. Questions were also asked regarding student behavior and avoidance in dining halls. Of the 287 students, 114 (39.7\%) reported that they always avoid ingesting food in which they reported an allergy, and $173(60.3 \%)$ reported they do not always avoid the food item to with they reported a food allergy (Greenhawt et al.). This reveals a followup question to be studied of why students are taking risks in eating food they know they are allergic to.

College is an exciting time in a young adult's life. College is the first experience, for many, living without parental supervision. There are an estimated 17.5 million students in college, 10.9 being full-time. Of these 17.5 million students, it is estimated that $436,000-700,000$ college student may have food allergies (Greenhawt et al., 2009). Data from the American College Health Assessment 2007 survey indicated that $51 \%$ of college students reported having a food allergy (Greenhawt et al.). Being cautious of food allergies becomes a responsibility of the individual and not of the parents. There are several concerns regarding this issue. First, it has been made evident from the research done by Greenhawt et al. (2009) that campus health 
services and campus dining services are often not notified or made aware of students' food allergies. A second concern is that students have reported taking risks and ingesting foods that they knew they were allergic to, thus increasing the chance of an allergic reaction. It has been recognized that colleges and universities are in potential need of education regarding food allergies (Greenhawt et al.). Food allergies may be a growing concern on college campuses with communication being less than optimal and students taking risks within dining services

\section{Food allergy accommodation policies in colleges and universities}

Sicherer (2017) studied food allergy accommodation on universities and college campuses. Eleven various staff members from university foodservice were interviewed from 73 different universities and colleges. Staff members interviewed included campus dietitians, foodservice managers, and marketing managers. Qualitative interviews were conducted and addressed operational aspects of the campus dining such as menu information, designated allergen- food production and access to ingredient lists for menu items. Sicherer discovered that $53(73 \%)$ of the universities had menus that contained information regarding the major allergens. Forty $(55 \%)$ of the universities had a designated allergen-safe food production area. Thirty-seven (51\%) of the universities had a designated allergen-safe storage area. Forty-six (63\%) provided access to an ingredient list for all menu items that were offered (Sicherer). Sicherer stated that this suggests that university and college campuses are aware of food allergy

prevalence and have policies and procedures in place to handle them. The author also suggested that the increase in food related allergic reactions are a result of a lack of communication between college students and food handlers (Sicherer). 


\section{Fatalities due to anaphylactic reactions to foods}

Fatal anaphylactic reactions due to food allergies are continuing to occur. An anaphylactic reaction is a severe reaction that can cause throat tightness, wheezing, chest tightness, trouble breathing, and tingling in the hands, feet, or lips. Fatalities due to ingestion of foods that cause an anaphylaxis response are a major problem. Bock, Munoz-Furlong, and Sampson (2001) worked with the American Academy of Allergy, Asthma, and Immunology and the Food Allergy and Anaphylaxis Network in order to analyze fatal cases of anaphylactic reactions due to food. Between the years 1994 and 1999 there were 32 fatalities reported in the United States to due to food allergies that caused anaphylaxis. The researchers reached out to the families of the deceased individuals.

A questionnaire was used to obtain information from family members regarding the details of the allergic reaction. Information about demographics, sequence of events from food ingestion to symptoms, treatment, information about the food ingested, history of asthma and allergy, current medications, and education of food allergies was collected. The 32 fatalities were then split into two groups. Group one contained 21 of the fatalities and information regarding the food ingested, epinephrine use, location, and history of allergy were known. Group two consisted of 11 of the fatalities and information regarding the food ingested and location of reaction was available, however the researchers could not be certain if epinephrine was used or if there was a known history of a food allergy. In group one, five (36\%) of the 21 fatalities occurred on a college campus and all five of those fatalities had prior history of an allergic reaction. In group two, three (27\%) of the 11 fatalities occurred on a college campus. It is unknown whether those three fatalities had prior history of an allergy. In total, 14 (44\%) of all 32 fatalities due to allergic 
reactions occurred in young adults ages 18-21. Bock et al. (2001) found that a large majority of the victims of the fatalities were young adults.

The authors repeated the study in 2007, after receiving reports of 31 fatal allergic reaction between the years 2001-2006. This time the fatalities were not split into two groups. It was identified that two $(6 \%)$ of the 31 fatalities occurred on a college campus. Two $(6 \%)$ of the fatalities occurred in an unknown location. Three (9\%) out of the 31 fatalities occurred in individuals ages 18-21 (Bock et al., 2007). It is imperative that education is given, and knowledge is improved for families, friends, and schools regarding food allergies and anaphylactic reactions (Bock et al.).

\section{Improving Food Allergy Management on Campuses}

Transitioning from adolescence to a young adult is a developmental period in one's life where responsibility is shifted to the individual. This responsibility includes the management of chronic conditions such as food allergies. Self-management of food allergies requires knowledge and understanding of food allergies and the symptoms of an allergic reaction. Fatal allergic reactions due to the ingestion of food is most common among adolescence and young adults (Dyer, O’Keefe, Kanaley, Kao, \& Gupta, 2018). Some colleges and universities are not well equipped and do not provide enough support for individuals with food allergies. Dyer et al. conducted a study in order to further understand the systems, structures, and policies for students with food allergies on college campuses. The author's used a qualitative research method conducting interviews with 26 stakeholders in campus management of food allergies. Themes that emerged from these interviews revealed that transition to college for students with food allergies would be improved by providing support for notification of other students about food 
allergies. Other ways to improve this transition includes establishing clearly defined roles and responsibilities of students and food management personnel and increasing campus awareness of food allergy signs and symptoms. The authors found that while many colleges offer support for students with food allergies in the dining hall, this does not always carry over to dorms or special social events. This causes students with food allergies to feel vulnerable and panicking to inform departments of their needs. Stress of students with food allergies can be reduced by creating a supportive community with individuals who are trained and aware of food allergies and their signs and symptoms (Dyer et al., 2018).

\section{Research and statistics}

Few research studies have been done regarding food allergies among college students. Research studies known regarding food allergies on a college campus include those done by Greenhawt et al. (2009) and Sicherer (2017). Based on the previous two studies and the statistics regarding prevalence of food allergies and allergic reactions related to food, it is evident that this is an important topic to understand. Food allergies grew $18 \%$ from 1997-2007 and up to 15 million people in the United States have food allergies (Centers for Disease Control and Prevention, 2013). About $20 \%$ of individuals with food allergies are diagnosed at the college age. Statistics predict that for a campus that serves 1,000 students, $40 \%$ of those students will have food allergies, and $30 \%$ of them will not have communicated these allergies with food handlers and food managers. Forty-one percent of individuals with food allergies have reported experiencing an allergic reaction (Winthrope, 2013). Food allergy reactions in a school is a topic that is not well known but is becoming increasingly important and noticed among schools and college campus'. College is when an individual student is on their own for the first time and do 
not have the guidance of their parents to help them navigate their food allergies. It is crucial to understand the communication of students and food managers in order to prevent severe reactions. The current study conducted was used to help further understand the communication of students and food managers concerning the presence of food allergies.

\section{METHODS}

A mixed method design using a quantitative and qualitative component was selected to collect data in order to obtain more of an understanding into the food allergy resources on campus. The researcher constructed a questionnaire that was piloted to senior dietetic students $(n=8)$ for clarity. Questions were then adjusted for clarity (see appendix A for the questionnaire). A convenience sample of undergraduate university students $(n=94)$ was recruited to complete the revised questionnaire. The questionnaire was administered, by the researcher, to three undergraduate classes on the campus of a Midwestern university. Data from the questionnaire addressed the presence of a known food allergy or intolerance, symptoms experienced during a reaction, and whether it was reported to campus food service. Data from the questionnaires were organized using a frequency distribution.

The researcher conducted 30-minute interviews with the campus dietitian and university food manager. Other food service employees were asked to participate but were unable. Questions asked included "How does a student go about communicating a food allergy/intolerance to the kitchen staff?" and "How does the university and Sodexo handle food allergy accommodations for students with food allergies?” Interview content was transcribed, coded and reviewed for themes related to food allergy communication and allergen friendly food availability. 


\section{RESULTS}

Recruited survey participants consisted of students ages 18-24 years. Of the survey participants $(n=94), 28(30 \%)$ were male and $66(70 \%)$ were female. Of survey participants, 36 $(38.3 \%)$ reported having a food allergy/intolerance and $58(61.7 \%)$ did not. Of the 36 who reported a food allergy/intolerance, $28(77.8 \%)$ did not communicate the allergy/intolerance to food service, $4(11 \%)$ did communicate an allergy/intolerance to food service, and $4(11 \%)$ did not respond to this question. Of the $28(77.8 \%)$ students who did not communicate their allergy/intolerance, $22(78.6 \%)$ reported to have found allergen friendly foods available on campus, $5(18 \%)$ did not find allergen friendly food available on campus, and $1(3.6 \%)$ did not respond to this question. Of the $4(11 \%)$ participants who did communicate a food allergy/intolerance, 3 (75\%) found allergen friendly foods available on campus, and $1(3.6 \%)$ did not find allergen friendly food on campus.

An interview was conducted with the university food service manager and the campus dietitian. Food service on campus is run by a food service company. Themes that emerged from the interview with Food Service Management revealed that students do report food allergies to food service, and there are multiple paths available to communicate food allergies/intolerances via the campus dietitian or student development on campus. Campus food service is aware of the increase of food allergy reactions on college campuses and once food allergies/intolerances are communicated, action is taken. Education on handling food allergies/intolerances for managers, kitchen staff, and students is ongoing. 


\section{DISCUSSION}

\section{Explanation of results}

The purpose of this research study was to understand the relationship between students reporting their food allergy and the availability of allergen friendly foods within a college campus foodservice. In order to understand the relationship between food allergy communication and allergen friendly food availability, the research study was guided by the following research question:

1. How does food allergy communication between students and food handlers impact the availability of allergen friendly foods on a college campus?

The results of this study determined that there was no impact of food allergy communication between students and food handlers on the availability of allergen friendly foods on campus.

Of the students who filled out the questionnaire $(n=94), 36(38.3 \%)$ have a food allergy or intolerance. Of those $36(38.3 \%)$, only $4(11 \%)$ communicated their food allergy or intolerance to food managers on campus. Twenty-eight (77.8\%) of the $36(38.3 \%)$ who have a food allergy did not communicate their food allergy to or intolerance to food managers on campus. However, of those 28 (77.8\%) who did not communicate their food allergy or intolerance, $22(78.6 \%)$ still found allergen friendly foods available on campus. The frequencies in the questionnaire suggested that there is no impact between communication of a food allergy or intolerance and availability of allergen friendly foods on campus.

The interview with food service management revealed that there are multiple pathways to communicate a food allergy or intolerance to food service management including speaking with a food service employee, contacting the campus dietitian, or going through student services on 
campus. Once a food allergy or intolerance is communicated, action is taken by the food service management by making all staff aware, creating a plated meal for the student, and guiding the student in navigating the dining hall to avoid a food related reaction. Food service management is aware of the increase of food allergy and intolerance reactions on this college campus and try to create a way to better serve their students by providing allergen friendly foods in campus dining. With the increase of food allergies and the increase of reactions on a college campus still being a concern (Winthrope, 2013), an emerging problem may be that college students are underutilizing the pathways available to communicate food allergies and intolerances and underreporting food allergies and intolerances to food managers. An emerging issue may be that allergen friendly food availably is also connected to the knowledge of an increase in food allergy and intolerance reactions as well as communication between students and food managers.

\section{Limitations}

One limitation of this study was the small sample size of students $(n=94)$. The students were all recruited from the Family and Consumer Sciences courses of a small Midwestern Christian university. The results may have been different if distributed among multiple universities located in various areas. The results are unable to be generalized to all college universities. The study also only used frequency distribution to analyze the data. Further research is needed to determine the relationship between food allergy communication and availability of allergen friendly foods.

In addition, the survey distributed to students was written by the researcher and was not validated. After contacting researchers from previous studies, the researcher was unable to identify a validated survey to be used in the research study. The results from the survey may have been different depending on the validation process. 


\section{Implication of Results}

Understanding the relationship between food allergy communication and availability of allergen friendly foods in university dining halls can be useful in trying to help decrease the prevalence of food related reactions on a college campus. Communication is vital in helping students navigate their way through a campus dining hall to avoid food related reactions and receive the nutrition they need. Without communication, food managers are unaware of the prevalence of food allergies on college campuses and cannot always provide what is needed to serve the students. This study highlighted that there is little communication between students and food handlers regarding food allergy and intolerances.

The study also highlighted the idea that the availability of allergen friendly foods might be related to the knowledge of the prevalence of food allergies and intolerances and increase in food relate reactions. This may be why the availability of allergen friendly foods may be found on a college campus. Understanding the impact and relationship of food allergy communication is important for being able to increase availability allergen friendly foods and decrease the prevalence of food related reactions.

\section{CONCLUSION}

Although there are paths for students to report allergies/food intolerances a small number of the sample of students actually reported. Reporting pathways are available but underutilized. An emerging problem may be that college students underreport food allergies. While the variety of allergen friendly foods are available to students not all students were aware of this availability. Availability of allergen friendly foods can improve through student communication with Foodservice. Availability of allergen friendly foods seemed to be connected to national increases in allergen/intolerance reactions and the willingness of Foodservice companies to make changes. 
More research in needed to further understand the relationship between food allergy communication and the availability of allergen friendly foods. 


\section{REFERENCES}

American Academy of Allergy Asthma and Immunology. (n.d.). Food allergy definition. Retrieved from https://www.aaaai.org/conditions-and-treatments/conditionsdictionary/food-allergies

Bock, S. A., Munoz-Furlong, A., \& Sampson, H. A. (2001). Fatalities due to anaphylactic reactions to foods. The Journal of Allergy and Clinical Immunology, 107(1), 191-193.

Bock, S. A., Munoz-Furlong, A., \& Sampson, H. A. (2007). Further fatalities caused by anaphylactic reactions to food, 2001-2006. Journal of Allergy and Clinical Immunology, 119(4), 1016-1018.

Centers for Disease Control and Prevention. (2013). Voluntary guidelines for managing food allergies in schools and early care and education programs. Washington, DC: US Department of Health and Human Services.

Collins, S. C. (2016). Practice paper of the Academy of Nutrition and Dietetics: Role of the registered dietitian nutritionist in the diagnosis and management of food allergies. Journal of the Academy of Nutrition and Dietetics, 116(10), 1621-1631.

Dobler, M. L. (1991). Food allergies. Chicago, IL: American Dietetic Association.

Dow, C. (2019). When food fights back: Clearing up confusion over foods allergies and intolerances. Nutrition Action Healthletter, 8-11.

Dyer, A. A., O’Keefe, A., Kanaley, M. L., Kao, L. M., \& Gupta, R. S. (2018). Leaving the nest: Improving food allergy management on college campuses. Annals of Allergy, Asthma \& Immunology, 121(1), 82-89. 
Food Allergy Research and Education (2014). About food allergies. Retrieved from http://www.foodallergy.org/about-food-allergies

Greenhawt, M. J., Singer, A. M., \& Baptist, A. P. (2009). Food allergy and food allergy attitudes among college students. Journal of Allergy and Clinical Immunology, 124, 323-327. doi:10.1016/j/jaci.2009.05.028

Koerner, C. B., \& Muñoz-Furlong, A. (1998). Food allergies: How to eat safely and enjoyably. New York, NY: Wiley \& Sons.

Sicherer, S. H. (2017). Food allergy in college and university students: Overview and management. Retrieved from https://www.uptodate.com/contents/food-allergy-incollege-and-university-students-overview-and-management\#H2769496882

Togias, A., Cooper, S. F., Acebal, M. L., Assa'ad, A., Baker, J. R., Jr., Beck, L. A., ... Boyce, J. A. (2017). Addendum guidelines for the prevention of peanut allergy in the United States: Report of the National Institute of Allergy and Infectious Diseases-sponsored expert panel. Journal of the Academy of Nutrition and Dietetics, 117(5), 786-793.

Winthrop, B. (2013). Managing food allergies in a campus setting. Tastings, 1-6. 
Appendix A

Student Questionnaire 


\section{Survey for Student Participants}

\section{$\underline{\text { Demographics }}$}

1. What is your age?

2. What is your gender?

3. What is your education level? Fr. Soph. Jr. Sr.

$\underline{\text { Student Survey Questions }}$

1. Do you have a food allergy? Yes I don't Know

2. Is it a diagnosed food allergy? Yes No

3. If it is not a diagnosed food allergy, is it Self- Diagnosed? $\quad$ Yes

4. Do you have a food Intolerance or Sensitivity? $\quad$ Yes No

5. What type of reaction occurs as a result of consuming allergen containing food? (Select all that apply)

Skin Rash

Swelling of lips, face, tongue, or throat

GI upset (abdominal pain, diarrhea, nausea, vomiting)

Wheezing or trouble breathing

N/A

6. Have you communicated your food allergy to the Sodexo kitchen? Yes No N/A

7. Are there allergen friendly foods available on campus? Yes No

8. Is it easy to find allergen friendly food on campus? $\quad$ Yes No N/A 
Appendix B

Qualitative Questions for Food Service Managers 


\section{Focus Group Questions for Food Managers}

1. How is the term food allergy defined by the University and Sodexo?

2. How does the University and Sodexo communicate information about handling special diets to students with food allergies?

3. Who is involved in helping a student make accommodations?

4. How does a student go about communicating a food allergy to the kitchen staff?

5. What qualifies a student for food allergy accommodation?

6. Is there documentation that a student must complete in order to request accommodations?

7. Are there written policies and procedures related to accommodations for food allergies?

8. If there are written policies and procedures, how long have these been in place?

9. How does the University and Sodexo handle food allergy accommodation for students with food allergies? 